La explicación histórica. Punto de quiebre entre el Relato histórico y la Narración histórica

Pablo César Ojeda Lopeda

páginas / año 13 - n 31 Enero - Abril / ISSN 1851-992X/ 2021

http://revistapaginas.unr.edu.ar/index.php/RevPaginas

DOI: http://dx.doi.org/10.35305/rp.v12i30.474

\title{
La explicación histórica. Punto de quiebre entre el Relato histórico y la Narración histórica ${ }^{1}$
}

\author{
Historical explanation. Break point between the historical text \\ and the story
}

\author{
Pablo César Ojeda Lopeda \\ Pontificia Universidad Católica de Chile; \\ Facultad de Educación (Chile) \\ pcojeda@uc.cl
}

\begin{abstract}
Resumen
El artículo plantea el concepto Explicación Histórica como eje que permite diferenciar entre un Relato Histórico con características narrativas y la Narración Histórica. Presenta cinco elementos extratextuales -la prueba documental, la conceptualización disciplinar, la conexión de eventos, la reflexividad crítica y el tratamiento con entidades-, y ejemplifica cómo aparecen en uno y otro género textual. Se concluye que el relato histórico es un texto límite que, siendo verosímil como cualquier producto narrativo, aspira a ser verdadero.
\end{abstract}

Palabras Clave

Explicación histórica; relato histórico; narración histórica; género.

\begin{abstract}
This paper argue that the Historical Explanation is the axis that allow differentiate between a Historical Text with narrative characteristics and a Story. Also, show five extratextual elements -documental prove, the disciplinary conceptualization, the connection of events, the critical reflexivity and the treatment with entities- and how appear in boths texts, the historical text and the story. This paper show examples about that elements in both texts. Like a conclusion, this paper statement that the historical text although it's plausible like any narrative text, he have the pretention of be true.
\end{abstract}

\section{Keywords}

Historical explanation; historical text; story, genre.

\footnotetext{
${ }^{1}$ Este trabajo hace parte del proyecto "Interacciones discursivas y desarrollo de la argumentación histórica en clases de historia en 3 o medio. Una mirada dialógica", financiado por CONICYT.
}

Esta obra está sujeta a la Licencia Reconocimiento-NoComercial-CompartirIgual 4.0 Internacional de Creative Commons. http://creativecommons.org/licenses/by-nc-sa/4.0/ 


\section{Pablo César Ojeda Lopeda}

\section{Introducción}

Desde mediados del siglo XX el Relato histórico fue asumido como una forma más como se concreta la narración (White, 1992, 2003). Este hecho generó que las líneas que dividían al relato histórico de otras formas de narración como la Narración histórica, v.gr. Novela Histórica, no fueran tan claras llegando incluso hasta plantear que entre uno y otro no existían mayores diferencias. Sin embargo, pasado un tiempo esas diferencias fueron emergiendo. El presente artículo plantea cómo se presentan tales diferencias en ambos géneros textuales.

En el contexto hispanoamericano autores como Araújo, Álvarez \& Medina (2013), Bonet (2005), Buxó (2011), Franco (2008), Matas (2004), han abordado las diferencias entre esos dos géneros; sin embargo, las han trabajado especialmente en el plano de retórico, sin presentar mayores evidencias que ejemplifiquen lo afirmado; además, al abordar aquello que diferencia ambos géneros textuales, lo han hecho de forma discreta, aislada, como si fueran expresiones que nada tienen en común.

Para intentar cubrir los vacíos de trabajos anteriores, este texto tiene la intención de: 1‥ Emplear como recurso didáctico ejemplos puntuales tomados tanto de relatos históricos, como de narraciones históricas, para evidenciar la diferencia entre uno y otro género textual. 2‥ Proponer que las diferencias entre ambos géneros textuales, no son eventos aislados, sino que son la expresión de algo mucho mayor que aporta a construir de manera integrada lo que Ricoeur (1995), denomina la Explicación histórica.

Para cumplir los propósitos mencionados, este texto se estructura de la siguiente manera: con base en la epistemología de la historia como telón de fondo, se realiza un breve recorrido por el desarrollo de la disciplina, planteando inicialmente la concepción positivista de la disciplina, hasta llegar a su postulación como disciplina narrativa e interpretativa. Esta primera parte se cierra haciendo alusión a las dificultades que se generaron al interior de la propia disciplina para entender las diferencias entre un relato histórico con características narrativas y una narración histórica. Posteriormente, se propone el concepto Explicación histórica como aquel desde el cual es posible generar las distinciones entre los géneros mencionados. Para lograr esa distinción, se examinan los diferentes elementos que componen dicho concepto. Para mayor claridad, se ejemplifica cada uno de dichos componentes indicando cómo emergen en algunos relatos históricos (v.gr. investigaciones históricas) y se contrastan con narraciones históricas (v.gr. novelas históricas).

\section{Cambio de perspectiva: del positivismo histórico al narrativismo histórico}

En el devenir de la historia su objeto de estudio no ha cambiado: El pasado. Desde la tradición positivista, o paradigma tradicional como lo denomina Burke (1996), se 


\section{La explicación histórica. Punto de quiebre entre el Relato histórico y la Narración histórica}

asumía que él era inalterable. La labor del historiador consistía entonces en dar cuenta de ese pasado "tal como fue", como lo propuso Ranke en su momento (Olábarri, 2013).

Desde esta propuesta, se asumía que el historiador se acercaba a las fuentes documentales, generalmente estatales, y estas entregaban los datos con los que él daba constancia del evento. Concebir la historia como disciplina del pasado "tal como fue", conllevaba también una manera particular de escribir acerca de ese pasado: La descripción. Esta forma de presentar un evento obliga al descriptor a mostrar aquello que está sucediendo frente a sus ojos, sin que sus valores interfieran en aquello que ha observado.

Tal perspectiva de la disciplina empezó a ser fuertemente criticada especialmente desde mediados del siglo XX. Las críticas a esa forma de ver el pasado y de hacer historia fueron planteadas desde diferentes frentes, dos de los cuales fueron la mirada polifónica de la historia y el planteamiento de la alineación ideológica del historiador, que a continuación se desarrollan brevemente.

Una crítica que se le hizo a la perspectiva positivista fue que ella era generalmente contada desde la perspectiva oficial y del ganador. Los "nuevos historiadores", comprendieron que el evento del pasado podía ser estudiado como un acto polifónico (Burke, 2010); es decir, desde las voces de aquellos que tradicionalmente no habían aparecido en la historia: mujeres, indígenas, esclavos, vencidos, inmigrantes, entre otros (Burke, 2010; Stradling, 2003), y cuyo punto de vista podía llegar a diferir acerca de cómo el pasado era comprendido, lo que abría las puertas a otras interpretaciones del mismo.

Otra crítica que recibió el positivismo histórico es que no daba tanta importancia a la carga ideológica del historiador. La concepción contemporánea de la historia reconocía que, al estudiar determinado evento histórico, el historiador lo hacía desde determinada "alineación ideológica" (Burke, 1996; Ricoeur, 1995; Sorgentini, 2003; White, 1992), que incidía en cómo él entendía y se acercaba al hecho histórico. Lo que ponía en evidencia ese aspecto es que el pasado no era algo dado, que existía per se, sino que era construido, creado por el historiador desde la postura que adoptaba.

Con esas críticas hacia la historia positivista, fue claro que el pasado que pretendía estudiar de ninguna manera era objetivo, finito y frente al cual el historiador debía posicionarse como mero observador que sólo daba cuenta del mismo.

Con el advenimiento de la perspectiva narrativa al campo de las humanidades, la historia empezó a ser considerada como una disciplina interpretativa (Coleman, 1989; Louch, 1969; Ricoeur, 1995; White, 1992); es decir, que el pasado es construido por el historiador desde determinadas perspectivas o interpretaciones, que de ninguna manera lo agotan. El historiador fue visto casi como un novelista que creaba refiguraciones e interpretaciones de ese pasado (Ricoeur, 1995, White, 1992), por lo que siempre que este último fuese revisitado, otras voces podrían aparecer, otras interpretaciones podían ser posibles. 


\section{Pablo César Ojeda Lopeda}

Al ser el pasado un evento construido, la descripción difícilmente podía ser considerada como la mejor manera para dar cuenta de él, toda vez que supone objetividad, neutralidad, univocidad, finitud. White (1992, 2003), planteó que la narración era la forma que mejor identificaba y caracterizaba a la disciplina histórica, y al texto histórico como dispositivo a través del cual se comunicaba su conocimiento. Siendo ello así, una pregunta que surgió fue: Si la narración es lo que da identidad a la Historia, ¿cómo aparece lo narrativo en el Relato Histórico?.

De acuerdo con White $(1992,2003)$, al igual que una novela, el relato histórico es un producto originado en la imaginación del historiador, tanto por el uso que hace de los hechos, como del lenguaje. Así como los hechos que componen una novela son ficciones de la mente del novelista, los hechos y datos con los que el historiador trabaja también son creaciones de éste, pues ellos no tienen una existencia propia; es la perspectiva interpretativa del historiador la que los "hace hablar", los ubica de determinadas maneras en su texto para que tengan sentido en todo el entramado del relato y aporten a la creación del significado en la obra.

A la perspectiva interpretativa del historiador, se suma el uso cuidadoso que hace de los diferentes recursos que el lenguaje proporciona, y desde los cuales él crea "una realidad que sólo puede ser imaginada más que percibida directamente" (White, 2003, pp.45).

Al proponer que el historiador interpreta los hechos y crea las realidades de forma discursiva como lo hace un novelista, la perspectiva narrativa logra que aquél deje de ser considerado como un observador pasivo como lo proponía la postura positivista de la disciplina (Araújo et al., 2013; Olabarri, 2013), y pase a convertirse en un diseñador del pasado.

Sin embargo, para algunos historiadores la perspectiva narrativa de la historia terminó por generar más problemas que los que parecía resolver. Al ubicar al relato histórico en el mismo plano de cualquier otro producto narrativo, y al historiador como un ficcionador del pasado, llegando casi a convertirse en un creador de falsedades (Chartier, Mediola \& Semo, 1996), el texto histórico perdía toda validez científica pues, al igual que una novela, no habría forma de verificar aquello que el historiador estaba declarando. Los géneros histórico y novelesco se confundían (Matas, 2004), y las líneas que antes demarcaban territorios claros, se habían difuminado al punto que resultaba difícil hacer la distinción entre unos y otros géneros textuales:

"La crisis de las grandes narrativas, la forma en la que hemos despedido al mayordomo después de tantos siglos de servicio, nos ha remitido a un modelo historiográfico en el que, parafraseando a Lichtenberg, resulta difícil distinguir la realidad de la ficción y las crónicas de las novelas". (Moscoso, Lucena \& Marcaida, 2010, pp. 353).

Sin olvidar el carácter narrativo que tiene el texto histórico, algunos epistemólogos e historiadores solicitaron precisar aquello que podría ayudar nuevamente a separar aguas entre ambos géneros (Araújo et al., 2013). La Explicación Histórica, y 


\title{
La explicación histórica. Punto de quiebre entre el Relato histórico y la Narración histórica
}

especialmente los elementos que la componen, aparece entonces como aquel constructo que ofrece luces para dilucidar qué características posee un texto tipo relato histórico y cómo esas características emergen en un texto tipo narración histórica.

\section{Límites a la narración. la explicación como punto de quiebre}

A pesar de existir un puente que vincula al texto narrativo con el histórico, cada uno permanece en su orilla. De acuerdo con Ricoeur (1995), aquello que marca la diferencia, pasa por cómo es asumida la explicación en el terreno de la narrativa y en el de la disciplina histórica:

\begin{abstract}
"En el plano de los procedimientos, la historiografía nace, en cuanto investigación ..., del uso específico que hace de la explicación. Aunque se admita .... que la narración es "auto-explicativa", la historia-ciencia separa de la trama de la narración el proceso explicativo y lo erige en problemática distinta. No es que la narración ignore la forma del ¿por qué? y del porque, pero sus conexiones siguen siendo inmanentes a la construcción de la trama ... Una cosa es explicar narrando y otra problematizar la propia explicación para someterla a la discusión y al juicio de un auditorio, si no universal, al menos considerado competente, compuesto en primer lugar, por los colegas del historiador". (Ricoeur, 1995, pp. 290)
\end{abstract}

La explicación es entonces el punto de quiebre que logra trazar una línea divisoria entre el relato histórico y una narración histórica. En términos generales, Ricoeur afirma que mientras la explicación narrativa encuentra su sustento al interior del propio texto ("es autoexplicativa"), la explicación histórica siempre ocurre de forma extra textual.

El relato histórico lleva a su lector fuera del texto: a las fuentes, a las interacciones con otros trabajos, entre otras características, con los que busca legitimar, dar validez a lo que está siendo afirmado. La narración histórica por su parte, no requiere de tales elementos extra textuales; las fuentes con las que fueron construidos este tipo de textos, así como los eventos o los sujetos a los que se alude, bien podrían no existir y no por ello este tipo de narración pierde valor.

Los elementos extra textuales que componen el relato histórico son la prueba documental, la conceptualización disciplinar, la conexión de eventos, la reflexividad crítica y el tratamiento con entidades. A continuación, se indica cómo emergen y de qué forma son empleados en los relatos históricos; a su vez, se ejemplifica el tratamiento que reciben tales elementos en ambos tipos de textos. 


\section{Pablo César Ojeda Lopeda}

\section{La prueba documental}

La explicación es un procedimiento que implica fundamentar aquello que está siendo afirmado, y la forma como el relato histórico logra hacerlo es a través de lo que se denomina el aporte de la "prueba documental" (Ricoeur, 1995, pp. 290).

La prueba documental, que no se agota en el documento escrito (Burke, 1996; 2005), alude a la fuente que el profesional en historia usa y presenta como fundamento de los argumentos que está planteando. La fuente no habla por sí misma, el historiador encuentra en ella vestigios de aquello que investiga; obtiene de ella datos que confirman o refutan hipótesis, que amplía el conocimiento que hasta ese momento se tenía de una temática histórica o de una sociedad. La prueba documental es la pieza clave a través de la cual decidir si una interpretación alcanzada es o no válida (Matas, 2004).

Por su parte, el texto tipo narración histórica, aún haciendo referencia a un hecho histórico particular, podría ser construido sin hacer alusión a fuente alguna y los eventos relatados podrían ser exagerados o minimizados más allá de sus proporciones sin que fuente alguna necesariamente avale tal tratamiento retórico. Por ejemplo, si un lector se acercara a la parte del texto de García Márquez "Cien años de soledad", en la que cuenta cómo el ejército colombiano asesinó a 3000 obreros, no le pediría a ese relato presentar pruebas fundamentadas en documentos que comprueben que efectivamente ese fue el número de acribillados. Tal cifra sería entendida como haciendo parte de la trama y del drama que el escritor quiso imprimirle a su relato (V. Posada, 1998). Es en ese sentido que Ricoeur (1995), afirma que la narración histórica es auto-explicativa, "inmanente(s) a la construcción de la trama" (pp. 290), y poco importa si realmente fueron 3000 los obreros masacrados; lo que importa en la narración histórica es que los elementos que la componen sirvan para darle mayor intensidad emotiva a la misma; importa más lo emocional, menos lo verídico.

Sin embargo, si ese mismo lector se acerca al texto de Wolf (citado por Acevedo, 2012), en el que relata "La masacre de las bananeras", le pediría al escritor presentar la prueba de lo que está afirmando cuando manifiesta que la cifra de obreros asesinados por el ejército colombiano en diciembre de 1928, fue de entre quinientos y mil. Frente a ese segundo texto, el lector ya no va a entender ese número como un dato de ficción sino como algo verídico y, en consecuencia, esperará del historiador que justifique el origen de la cifra, en cuáles fuentes se basó para proponerla. Anticipando esa posible pregunta que un lector de un relato histórico podría plantear, el historiador deberá decir que tales números provienen de los archivos desclasificados por el gobierno de los Estados Unidos; que en esos documentos aparecen los comunicados de los representantes de la United Fruit Company que a su vez recogieron los testimonios de oficiales norteamericanos, de militares y de políticos colombianos de la época, en los que se hablaba de tal cantidad de muertos. El historiador en su texto no sólo dirá de cuál fuente tomó sus datos, sino que podría 


\section{La explicación histórica. Punto de quiebre entre el Relato histórico y la Narración histórica}

incluso indicarle al inquieto lector cómo él mismo podría eventualmente acceder a tales archivos, a la prueba documental con cuya información construyó su relato.

Si un buen texto narrativo se caracteriza por el uso que hace en su relato de la trama, para cuya construcción apela a los más diversos recursos del lenguaje; un buen texto histórico se caracteriza tanto por el uso de esos mismos recursos, como por el empleo preciso de la prueba documental (Bonet, 2005).

\section{Conceptualización disciplinar}

Entiéndase por Conceptualizacion disciplinar el proceso que implica emplear los términos propios de la disciplina científica en un (con)texto técnico para comprender y explicar o dar cuenta del fenómeno de estudio.

Para el desarrollo de la explicación histórica, el historiador debe hacer uso adecuado de los conceptos disciplinares (Franco, 2008) cuyos significados han sido consensuados al interior de la disciplina. Esos conceptos disciplinares actúan como "dispositivos heurísticos" (Bonnell, 1980), con los que intenta acercarse al hecho histórico. De acuerdo con autores como Limón (2002) y Van Drie y Van Boxtel (2008), los conceptos que se emplean en la disciplina histórica son de dos tipos: sustantivos y metodológicos.

Los conceptos sustantivos son empleados en el relato histórico para hacer referencia a estructuras, períodos o fenómenos históricos. En ese sentido términos como revolución francesa, impero, edad media, etc. son conceptos sustantivos. Los conceptos metodológicos o metaconceptos, son los términos empleados por los historiadores para investigar y describir procesos históricos. Conceptos como fuente, cambio, causación, entre otros (Limón, 2002; Van Drie y Van Boxtel, 2008), son conceptos metodológicos o metaconceptos.

Mientras el relato histórico hace uso de un lenguaje técnico, la narración histórica por su parte acude principalmente al lenguaje común (Franco, 2008), como uno de los recursos del novelista para logar que su texto sea verosímil, creíble para el lector. A diferencia del relato histórico, la narración histórica emplea un lenguaje divulgativo (Franco, 2008), pues está dirigido intencionalmente a un público seguramente más amplio que el académico, que espera encontrar contenido relacionado con un pasado en un lenguaje que lo haga fácilmente digerible.

En los siguientes dos fragmentos de textos, quiero llamar la atención sobre la expresión Don y el tratamiento que recibe en uno y otro tipo de texto.

"Bastaba trasponer el umbral de una taberna para que una red de silencio repentino cayera sobre los hombres de don Hernando" (Baccino, 1989, pp. 5)

"Se han hecho famosas además las burlas despiadadas que recogió, todavía en el siglo XVII, Juan Ruiz de Alarcón, el gran autor dramático nacido en México, de familia hidalga, por el don que anteponía a su apellido. Por eso se ha supuesto que el uso de los indianos contribuyó a la generalización del don en la Península 


\title{
Pablo César Ojeda Lopeda
}

("en todos los oficios, artes y estados se ha introducido el don", "yo he visto sastres y albañiles con don", decía Quevedo). Es posible que contribuyera efectivamente. De todos modos, hemos visto que también en Italia se generalizaba el don ya en el siglo XVI. La democratización de los tratamientos es además un proceso general en todas las lenguas modernas, unido a la transformación social de los últimos tiempos." (Rosenblat, 1964, pp. 220-221).

En el primer fragmento, tomado de la novela "Maluco. La novela de los descubridores", su escritor Napoleón Baccino, emplea la palabra "don", sin otra intención que la de acompañar el nombre de un personaje, para indicar seguramente su posición social y el respeto que el personaje imponía. En el segundo fragmento, tomado del trabajo del lingüista e historiador Ángel Rosenblat (1964), la expresión "don" es ubicada como objeto de estudio. El experto emplea tanto conceptos sustantivos como "siglo", como metaconceptos tales como "democratización", "proceso", "transformación social", para ejemplificar un proceso histórico manifestado en el lenguaje, que permite dar cuenta de cambios sociales y culturales en la época colonial.

\section{Conexión de eventos}

En todo texto narrativo, novelesco o técnico, las situaciones y eventos que se relatan deben relacionarse unos con otros, esto da coherencia al escrito. Sin embargo, mientras la conexión de eventos en la narración histórica ocurre especialmente al interior del texto, la del relato histórico debe ir más allá del propio del texto en al menos dos sentidos: relacionar los eventos que trata con otros más generales y, relacionar el texto con otros relatos históricos (Ricoeur, 1995).

En el relato histórico, el evento histórico abordado no puede ser presentado como un fenómeno aislado sino que, siendo específico, logre establecer aquello que relaciona y comunica su trabajo con contextos y eventos históricos más amplios. Considérese el siguiente fragmento:

\begin{abstract}
"El 22 de junio de 1948 fue aprobada en Chile la Ley por la Defensa Permanente de la Democracia, conocida popularmente como la Ley Maldita. Este apartado legal proscribió al Partido Comunista y significó que sus militantes fueran perseguidos, encarcelados, torturados y exiliados. Fue impulsada por el presidente Gabriel González Videla, quien había sido electo en 1946 gracias al apoyo de una coalición política integrada por el Partido Radical, el Partido Demócrata y el propio Partido Comunista. Según la historiografía, esta disposición legal fue una de las primeras manifestaciones en Chile del nuevo escenario que la llamada Guerra Fría expandía por el continente". (Rivera, 2017, pp. 210)
\end{abstract}

En este apartado, el historiador Sebastián Rivera instala su trabajo alrededor de los exiliados chilenos en un escenario más amplio. Vincula los efectos de un hecho 


\section{La explicación histórica. Punto de quiebre entre el Relato histórico y la Narración histórica}

puntual ocurrido en Chile, la aprobación en 1948 de la denominada "ley maldita", con las corrientes políticas de la Europa de mediados del siglo XX, que generaron la polarización del mundo occidental en lo que se conoce como la Guerra Fría. Esta relación que conecta explícitamente eventos específicos ("ley maldita" de 1948 en Chile), con otros más generales (Guerra fría), es propia de todo relato histórico.

El relato histórico, además de poner en relación eventos locales con otros más generales, busca a su vez vincularse con otros trabajos disciplinares. Al respecto, afirma Ricoeur (1995), "no es ni inútil ni insensato el trabajo de aproximación capaz de acercar a esta idea los resultados concretos alcanzados por la investigación individual o colectiva" (pp. 292). La forma que puede adquirir la relación intertextual que establece el relato histórico con otros trabajos similares es amplia: los rectifica, los complementa, los refuta, los amplía, entre otras muchas opciones. En el trabajo de Robledo (2018) acerca de la pintura histórica en Colombia a mediados del siglo XIX, el autor comenta que lo que se ha producido en el país sobre el tópico que le interesa estudiar, se ha ocupado más de lo iconográfico y lo iconológico. Al hacer esto en su relato, él plantea el estado del arte de su problemática, comprometiéndose además a ampliar el conocimiento que sobre ese tipo de arte existe, ocupándose de las dimensiones sociales en las que tal pintura se generó, que son las que aún no han sido suficientemente trabajadas en la historiografía colombiana y que él se compromete a investigar.

En conclusión, la construcción de la explicación histórica demanda que el relato histórico muestre claramente la relación que establece con macroeventos sociales, políticos o culturales, a la vez que la relación que guarda con otros relatos históricos. Acerca de la narración histórica, si bien no puede negarse que da cuenta de un contexto social, cultural y político y a su vez, los elementos contextuales la permean, no tiene necesidad de plantear explícitamente cuáles son esos vínculos con aquellos eventos históricos más amplios, ni mucho menos con otros textos de ficción histórica. Estas últimas ideas aparecen claramente ejemplificadas en el texto de Aguado (2004), sobre la novela "El estrangulador", del escritor Manuel Vásquez Montalbán:

\footnotetext{
"Con la publicación en 1994 de El estrangulador, Manuel Vázquez Montalbán vuelve por los derroteros de sus escritos "subnormales," por aquellos escritos cuya innovación formal vanguardista producía textos incoherentes, sin sentido, absurdos, no aptos para personas "normales." De hecho, respondían a una realidad cuyos parámetros sólo podían entenderse no desde la racionalidad, sino desde la más absoluta ausencia de la misma, desde la desorientación en las referencias culturales y políticas que hasta no hacía mucho habían marcado el período de la guerra fría. El intelectual o el escritor no hacía otra cosa que reproducir en sus escritos la falta de armonía del mundo, que no era otra que la de un sistema económico irracional en su mercantilización de las relaciones humanas $-\mathrm{y}$ de sus productos culturales- $-\mathrm{y}$ en sus propuestas de un individualismo excesivo". (Aguado, 2004, pp. 23).
} 


\section{Pablo César Ojeda Lopeda}

En ese texto es Aguado, situado en la posición de crítico literario, el que establece las conexiones de la obra de Manuel Vásquez con un contexto más amplio como el de la guerra fría. No es el escritor de "El estrangulador" quien al interior de su propia obra manifieste por qué su texto responde a las características sociohistóricas de un determinado contexto, o cómo se relaciona con ese contexto; es otro que está situado más allá de la obra, el que devela esas relaciones pues la propia novela no puede hacerlo, ni tiene por qué hacerlo. Si bien desde Bajtin (2017), es claro que la obra literaria y cualquier enunciado se relaciona otros, esa relación no tiene necesidad de aparecer de manera explícita en ningún texto narrativo. El relato histórico en cambio no puede darse ese lujo, en él deben presentarse explícitamente los macroeventos con los que el evento estudiado se relaciona, y cómo se alínea o en qué se separa y diferencia de otros trabajos.

\section{Reflexividad crítica ${ }^{2}$}

La construcción de la explicación histórica nace a la luz de un posicionamiento epistemológico adoptado por el historiador. Este posicionamiento le implica una alineación ideológica, un modo explicativo y/o una postura que adopta y desde la cual se propone abordar su objeto de estudio (Burke, 1996; Ricoeur, 1996; Sorgentini, 2003; White, 1992).

La postura epistemológica adoptada, generalmente es declarada por el historiador, le marca un derrotero, tiñe sus observaciones y las conclusiones a las que puede llegar (Ferguson, 2006).

En el prefacio de su texto "el queso y los gusanos", Ginzburg (1999) señala claramente su postura epistemológica. Después de indicar por qué tres tradiciones de entender el concepto "cultura popular" -representadas por Mandrou, Bolleme y Foucault-, son ambiguas, declara cuál es la que él comparte: "Es mucho más valiosa la hipótesis formulada por Bachtin de una influencia recíproca entre cultura de las clases subalternas y cultura dominante" (Ginzburg, 1999, p. 6), al tiempo que reconoce las limitaciones técnicas que tal postura encierra: "Aunque precisar el modo y el momento de tal influencia (...) significa afrontar el problema con una documentación que, en el caso de la cultura popular, como hemos señalado, es casi siempre indirecta" (Ginzburg, 1999, pp. 6). La postura de Ginzburg implica que en las fuentes estudiadas intentará encontrar evidencia en la que la postura dominante y la popular se permean mutuamente.

Esas "declaraciones ideológicas" no es algo que se le pida hacer al escritor que se dedique a la creación narraciones históricas. Este tipo de escritor no indica al interior de su obra cuál es la postura epistémica que comparte, ni si quiera a qué

\footnotetext{
${ }^{2}$ Este elemento recibe diferentes nombres: Perspectiva particular (Burke, 1996), Aspectos éticopolíticos intrínsecos (Sorgentini, 2003), Implicación ideológica, en White (1992).
} 


\section{La explicación histórica. Punto de quiebre entre el Relato histórico y la Narración histórica}

corriente literaria adhiere. El narrador tampoco está en la obligación de hacerlo, pero si llegara a presentar su postura ideológica, ella no sería evidencia de que tal postura representa la del escritor. Lo anterior, no sugiere que el escritor carezca de una postura epistémica, eso es imposible, es solo que no es en su obra donde él hace explícita su alineación ideológica.

\section{Tratamiento con entidades}

Mientras que en la narración histórica la acción le es endilgada a tales o cuales personajes como sujetos de la acción y/o de intención (Bruner, 1988; Ricoeur, 1995), en el relato histórico tal agentividad en forma de sujetos particulares no existe. Pareciera paradójico que un texto con características narrativas, no contenga personajes: "Así, parece que la nueva historia no tiene personajes, pero sin personajes no podría seguir siendo una narración." (Ricoeur, 1995, pp. 293); ¿cómo resolver esta circunstancia?

En el relato histórico, el personaje pasa a ser ocupado por entidades de las que el historiador se sirve para sustentar suacercamiento yexplicación del hecho histórico y que inciden en el devenir de las sociedades (Ricoeur, 1995). Estas entidades son las fuerzas sociales que son mucho más que el resultado de la suma de muchas individualidades particulares: son las circunstancias económicas, los intereses geopolíticos, los cambios en la tecnología, entre otros, los "personajes" que constituyen la narración en Historia.

En el acercamiento que Ricoeur (1995), hace a la obra de Braudel, ubica al Mediterráneo como un personaje que atraviesa - ¿o es atravesado?- por una serie de circunstancias y fuerzas que ejercen algún tipo de influencia en él y van marcando su rumbo.

Aunque con menor intensidad, las fuerzas sociales también son objeto de tratamiento en textos como las biografías de sujetos que han sido determinantes en algunos eventos y momentos históricos. El historiador Inglés John Lynch, autor de estudios biográficos sobre San Martín y Bolívar, afirmó en una entrevista que le hicieran a propósito de las revoluciones hispanoamericanas: "Los libertadores respondieron a condiciones, y comprendieron las condiciones perfectamente" (Moreno, 2010). Incluso en obras que se les dedican a algunos personajes históricos, si bien la atención está centrada en ellos, en su ideario, el historiador no puede dejar de poner en juego las circunstancias que ejercieron algún tipo de influencia para explicar la acción del sujeto.

A diferencia de lo que ocurre con el relato histórico, la narración histórica gravita sobre los personajes como sujetos textuales de acción e intención (Bruner, 1988; Ricoeur, 1995). Es sobre personajes que el texto narrativo se construye incluso cuando parece que no los hubiera (Sánchez, 1998). 


\section{Pablo César Ojeda Lopeda}

\section{Conclusión}

El pasado no existe en sí mismo, no es algo que le haya sido conferido al hombre como objeto inamovible, sino que es algo que él construye y reconstruye de manera permanente. Esta posibilidad de refigurar los eventos está del lado de todo acto narrativo cuya intención es la de ser verosímil (Bruner, 1988), y la manera como se escribe el relato histórico busca esa verosimilitud: intenta convencer al lector de la trama que se desarrolla al interior del texto, tal y como lo hace cualquier otro producto narrativo.

Sin embargo, esa misma posibilidad de recrear el pasado fue la que inicialmente hizo difícil ver las diferencias entre la narración histórica creada por el novelista, especialmente la novela histórica, y el relato histórico creado por el historiador. No obstante, si bien no puede negarse el carácter creador que tiene el relato histórico, tampoco puede ser confundido con otros productos narrativos, pues tiene sus especificidades.

A pesar de la libertad de la que goza el historiador al crear el evento histórico, la perspectiva que va a adoptar, las voces que privilegiará, o el tratamiento que hará de las fuentes, se encuentra a su vez sujeto a las convenciones propias de su disciplina; convenciones necesarias para construir la explicación histórica, que le demandan siempre elaborar su texto considerando elementos extra textuales como el tratamiento de las fuentes históricas o el uso adecuado del tecnolecto, entre otras características.

Todas estas características hacen que el relato histórico sea considerado como un tipo de texto límite que, siendo verosímil como cualquier producto narrativo, a la vez deba ser verdadero; aspiración a la que ningún texto histórico puede renunciar.

\section{Bibliografía}

Acevedo, T. (30 de abril de 2012). El tamaño sí importa. El Espectador. Recuperado el 12 de abril de 2018 Recuperado de https://www.elespectador.com/noticias/judicial/el-tamano-si-importa-articulo$\underline{342860}$

Aguado, T. (2004). Ni El estrangulador ni el hombre total: Manuel Vásquez Montalbán y la historia de Boston. Arizona Journal of Hispanic Cultural Studies, 8(1), 23-40

Araújo, C., Álvarez, M. y Medina, C. (2013). Verdad y ficción en la historia: el debate entre Hayden White y Roger Chartier. Cuadernos, 43, 33-42. 


\section{La explicación histórica. Punto de quiebre entre el Relato histórico y la Narración histórica}

Baccino, N. (1989). Maluco. La novela de los descubridores. La Habana: Casa de las Américas.

Bajtín. M (2017). Problemas de la poética de Dostoievski. México: Fondo de Cultura Económica.

Bonnell, V. (1980). The Uses of Theory, Concepts and Comparison in Historical Sociology. Comparative Studies in Society and History, 22(2), 156-173.

Bruner, J. (1988). Realidad mental y mundos posibles. Los actos de la imaginación que dan sentido a la experiencia. (1ํㅡㄹ. ed.). Barcelona: Gedisa.

Bonet, M. (2005). La narración histórica en la teoría de Paul Ricoeur. Fragmentos de un debate.E-1@tina, Revista electrónica de estudios latinoamericanos, 3(12), 47-67

Burke, P. (1996). Obertura: La nueva historia, su pasado y su futuro. En Burke, P. (Ed.); Formas de hacer historia (2ª . Ed., pp. 11-37). Madrid: Alianza editorial.

Burke, P. (2005). Visto y no visto. El uso de la imagen como documento histórico. Barcelona: Crítica.

Burke, P. (2010). Cultural History as polyphonic history. ARBOR, Ciencia, Pensamiento y Cultura, 186(743), 479-486.

Buxó, J. (2011). De la historia a la literatura. Verdad o ficción. Revista de la Universidad de México, 83, 14-20.

Chartier, R., Mediola, A. \& Semo, I. (1996). El malestar en la historia. Fractal, 3(1), 153-175.

Coleman, A. (1989). Historia y narración: ensayos de filosofía analítica de la historia. Barcelona: Paidós.

Ferguson, W. (2006). The renaissance in historical thought: five centuries of interpretation. Toronto: University of Toronto Press.

Franco, G. (2008), Historia y narración histórica. Algunas reflexiones". En Franco, G. \& LLorca, F. (edas.); Las mujeres entre la realidad y la ficción. Una mirada feminista a la literatura española (pp.17-37). Granada: Colección Feminae, Servicio de Publicaciones de la Universidad de Granada

Ginzburg, C. (1999). El queso y los gusanos. El cosmos según un molinero del siglo XVI. (3‥ Ed.). Barcelona: Muchnik editores S.A.

Limón, M. (2002). Conceptual change in history. En Limón, M. \& Mason, L. (Eds.), Reconsidering conceptual change. Issues in theory and practice (pp. 259-289). Dordrech: Kluwer Academic Publisher. 


\section{Pablo César Ojeda Lopeda}

Louch, A. (1969). History as narrative. History and theory, 8(1), 54-70.

Matas, A. (2004). Verdad narrada. Historia y ficción. Historia, Antropología y fuentes orales, 31, 119-128.

Moreno, J. (2010). John Lynch y las revoluciones hispanoamericanas. Recuperado de http://reporterodelahistoria.blogspot.com/2010/09/john-lynch-y-lasrevoluciones.html

Moscoso, j., Lucena, M. \& Marcaida, J. (2010). Presentación historia polifónica. Un homenaje a Peter Burke. ARBOR, Ciencia, Pensamiento y Cultura, 743, 353-355.

Olábarri, I. (2013). Las viscisitudes de Clío (Siglo XVIII-XXI). Ensayos historiográficos. Salamanca: Ediciones Universidad Salamanca.

Posada, E. (1998). La novela como historia. Cien años de soledad y las bananeras. Boletín cultural y bibliográfico, 35(48), 3-19.

Ricoeur, P. (1995). Historia y Narración. En Tiempo y narración I. Configuración del tiempo en el relato histórico (pp.163-371). México: Siglo XXI.

Rivera, S. (2017). El otro exilio chileno en México y Guatemala, 1948-1951. Militancia transnacional en los orígenes de la guerra fría. Historia, 50(1), 209-240.

Robledo, S. (2018). Pintura histórica y retratos de próceres en Colombia durante el siglo XIX: Ausencia de apoyo público e importancia de las iniciativas privadas. Historia y sociedad, 34, 77-102.

Rosenblat, Á. (1964). Base del español de América: nivel social y cultural de los conquistadores y pobladores. Trabajo presentado en la Primera Reunión Latinoamericana de Lingüística y Filología, Viña del Mar, 171-230. Recuperado de https://lenguasmodernas.uchile.cl/index.php/BDF/article/download/49443/519 $\underline{04}$

Sánchez, F. (1998). Teoría del personaje narrativo (Aplicación a El amor en los tiempos del cólera). Didáctica, 10, 79-105

Sorgentini, H. (2003). Reflexión sobre la memoria y autorreflexión de la historia. Revista brasileira de história, 23(45), 103-128.

Stradling, R. (2003). Multiperspectivity in history teaching: a guide for teachers. Germany: Council of Europe.

Van Drie, J. \& Van Boxtel, C. (2008). Historical Reasoning: Towards a Framework for Analyzing Students' Reasoning about the Past. Educational Psychology Review, 20(2), 87-110. 
La explicación histórica. Punto de quiebre entre el Relato histórico y la Narración histórica

White, H. (1992). Metahistoria, la imaginación histórica en la Europa del siglo XIX. México: Fondo de Cultura Económica.

White, H. (2003). El texto histórico como artefacto literario y otros escritos. Barcelona: ICE, Universidad de Barcelona.

Recibido: 26/05/2020

Evaluado: $13 / 07 / 2020$

Versión Final: 31/07/2020 